\title{
RESENHA DA OBRA "ENSINANDO A TRANSGREDIR: A EDUCAÇÃO COMO PRÁTICA DA LIBERDADE"
}

Maciana de Freitas e Souza ${ }^{i}$ Patricia Lorena Raposo ${ }^{\text {ii }}$

Resumo: O livro "Ensinando a transgredir: a educação como prática da liberdade," de bell hooks, é o objeto de análise da presente resenha. Esta obra tem como proposta analisar os efeitos do colonialismo no campo educacional. Além disso, a autora enfatiza a perspectiva crítica e decolonial como um possível caminho para a promoção da liberdade. A leitura é conduzida por reflexões acerca da prática pedagógica como um lugar político e de resistência.

Palavras-chaves: Educação; Colonialismo; Liberdade.

\section{CRITICAL REVIEW OF THE WORK "TEACHING TO TRANSGRESS: EDUCATION AS A PRACTICE OF FREEDOM"}

\begin{abstract}
The book "Teaching to Transgress: Education as a Practice of Freedom," from bell hooks, is the subject of this review. This work aims to analyze the effects of colonialism in the educational field. In addition, the author emphasizes the critical and decolonial perspective as a possible way to promote freedom. Reading is led by reflections on pedagogical practice as a political and resistance place.
\end{abstract}

Keywords: Education; Colonialism; Freedom.

hooks, bell. Ensinando a transgredir: a educação como prática da liberdade. São Paulo Martins Fontes, 2013.

O livro "Ensinando a transgredir: A educação como prática da liberdade”, de bell hooks, apresenta uma análise crítica da prática pedagógica tradicional e ressalta a importância do fazer educativo com vistas a autonomia dos sujeitos sociais, tendo como base o referencial teórico do educador Paulo Freire. Assim, propõe abordar as diferentes disputas de sentidos acerca da Educação e o papel dos(as) professores(as) nesse processo.

Gloria Jean Watkins, conhecida como bell hooks, é escritora, educadora, feminista e ativista social estadunidense. O seu pseudônimo grafado em letras minúsculas é uma homenagem aos sobrenomes da mãe e da avó. O livro apresenta a sua trajetória como 
professora, os desafios do colonialismo e as interfaces com a Educação, bem como a relevância do conhecimento crítico e do feminismo intersecional 3 para a construção de um ensino radicalmente democrático.

bell hooks inicia o seu percurso apresentando os impactos do colonialismo no campo da educação. Para essa pesquisadora, no tecido social, existe uma manutenção das estruturas hierárquicas que legitima as opressões das minorias étnicas e estas atravessam o espaço educacional. Desse ponto de vista, faz-se necessário um ensino pautado numa perspectiva decolonial, crítica e feminista. De acordo com a autora (2013, p. 28), a pedagogia engajada é mais exigente que a pedagogia crítica ou feminista convencional. Ao contrário das duas, ela dá ênfase ao bem-estar, contribuindo para produzir novas formas de resistência.

Como assinalado pela autora, é importante que a educação seja constituída numa percepção crítica sobre a realidade social para a construção de ações transformadoras. Assim, é relevante que esteja vinculada a um projeto democrático e político e isso significa intervir com reflexões e respostas concretas junto aos diferentes grupos sociais subalternizados, bem como questionar a narrativa eurocêntrica que fortalece o racismo institucional. Nessa perspectiva, pelas suas vivências em sala de aula como estudante e professora negra, formula críticas ao processo formativo, marcado por ações que sustentava relações de poder.

Nas palavras da educadora (idem, p. 30):

É certo que eu era ingênua ao imaginar, durante o ensino médio, que recebia orientação espiritual e intelectual da parte de escritores, pensadores e acadêmicos no contexto universitário. Encontrar uma tal coisa seria o mesmo que descobrir um tesouro precioso. Aprendi, junto com os outros alunos, a me dar por contente que se encontrasse um professor interessante capaz de falar de maneira envolvente. A maioria dos meus professores não estavam nem um pouco interessados em nos esclarecer. Mais que qualquer outra coisa, pareciam fascinados pelo exercício do poder da autoridade dentro do seu reininho - a sala de aula.

Destarte, reforça que a "educação engajada" não se trata de uma educação normativa, que se baliza por deveres e obrigações, mas um processo que tem entre seus critérios exercer a liberdade e promover o diálogo. Diante da dívida histórica do Estado para as pessoas de minorias étnicas, garantir educação nesses princípios é uma das funções mais importantes do processo formativo. A educação decolonial e feminista pode contribuir desse modo para fazer 
da sala de aula um contexto democrático em que todos sintam a responsabilidade de contribuir é um objetivo central da educação transformadora - complementa (ibidem, p. 56).

Nessa perspectiva, as considerações da pesquisadora reforçam a construção de uma pedagogia emancipatória a favor da luta antirracista e que possa fortalecer o Estado Democrático de Direito. Para essa autora, a academia - e a escola - deve assumir essa responsabilidade, conduzindo práticas educativas com vistas à superação do racismo. Nesse contexto, assinala (ibidem, p. 52) que é preciso instituir locais de formação onde os professores tenham a oportunidade de expressar seus temores e, ao mesmo tempo, aprender a criar estratégias para abordar a sala de aula e o currículo multiculturais. Nesse sentido, o processo educativo deve contribuir para a criação de ações inclusivas, garantindo o reconhecimento dos grupos subalternizados, tendo como objetivo promover o exercício da criticidade e o respeito à diversidade.

Baseada nesse propósito, a produção ressalta a importância da teoria crítica para a construção de uma "educação engajada" que possa compreender a dinâmica social e as lutas sociais, com vistas à consciência coletiva. Para a educadora, no sistema educacional, mesmo com o debate do multiculturalismo, a prática pedagógica tradicional tem permanecido e contribui para a manutenção dos princípios da colonialidade e afirma que (ibidem, p. 51):

Apesar de o multiculturalismo estar atualmente em foco em nossa sociedade, especialmente na educação, não há, nem de longe, discussões práticas suficientes acerca de como o contexto da sala de aula pode ser transformado de modo a fazer o aprendizado uma experiência de inclusão.

Podemos compreender que as ações baseadas no ensino tradicional moldam desigualdades, sua lógica está voltada à manutenção do sistema vigente ao priorizar o conhecimento ocidental, ou seja, não oportuniza uma produção de conhecimento, o protagonismo e a cidadania política das minorias étnicas. Assim, é importante reconhecer que as práticas tradicionais silenciam as vozes de indivíduos dos grupos marginalizados complementa (ibidem, p. 110), por essa razão, pontua a importância do trabalho pedagógico multicultural como um ato ético e político.

Ao longo do texto, hooks relata que a vivência das práticas pedagógicas de Paulo Freire, bem como a sua participação no movimento feminista, foram questões fundamentais para a construção de um saber de resistência. Nesse contexto, promove uma reflexão sobre a 
falta de reconhecimento da produção intelectual das autoras negras, bem como a inscrição da lógica colonial no contexto de produção do conhecimento. Em face disso assinala:

Visto que a produção feminista por parte de acadêmicas negras sempre foi marginalizada, tanto em relação à hegemonia acadêmica existente, quanto à corrente principal do feminismo, aquelas entre nós que creem que esse trabalho é crucial para qualquer discussão imparcial da experiência negra têm de intensificar seu esforço de educação em prol da consciência crítica. Aquelas acadêmicas negras que começaram a tratar de questões de gênero enquanto ainda eram ambivalentes em relação à política feminista e agora cresceram, tanto em sua consciência quanto em seu comprometimento, têm o dever de se mostrar dispostas a discutir publicamente as mudanças no seu pensamento. $(2013$, p. 172)

A pesquisadora reconhece que o modelo educacional hegemônico não somente invisibiliza as mulheres negras, mas também se apresenta como prova concreta de que o racismo institucional se fortalece na dinâmica social. Apesar da relevância dos debates multiculturais, a educação tradicional reforça o silenciamento desse grupo, contribuindo assim para a manutenção das hierarquias raciais e as desigualdades de gênero. Por isso, ressalta (idem, p. 96):

Dentro dos movimentos feministas revolucionários, dentro das lutas revolucionárias pela libertação dos negros, temos de reivindicar continuamente a teoria como uma prática necessária dentro de uma estrutura holística de ativismo libertador.

Dando continuidade ao debate, hooks enfatiza a importância dos(as) professor(as) ampliarem essas discussões com os(as)alunos(as) com vistas à transformação das estruturas. A educação na perspectiva dessa educadora compreende uma prática educativa libertadora e emancipatória, na qual os sujeitos aprendem uns com os outros em um constante processo de observação crítica sobre a realidade. Assim, a escola deve ser vista como um lugar de empoderamento coletivo e de transformação social.

Para a autora, a noção tradicional de estar na sala de aula é de um professor atrás de uma escrivaninha ou em pé à frente de uma classe, imobilizado. Estranhamente isso lembra o corpo de conhecimento firme e imóvel que integra a imutabilidade da própria verdade (Ibidem, p. 184). Nesse sentido, o modelo tradicional de ensino ainda sustenta a narrativa que cabe somente ao professor a validação do conhecimento. Diante de tal contexto, a educação 


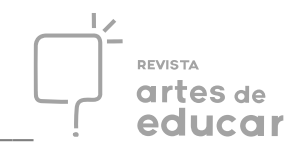

engajada visa dar protagonismo às vozes historicamente silenciadas, tanto no âmbito acadêmico como em demais espaços institucionais e apresenta a ideia de que todos, independente de formação, temos uma função no processo de produção e compreensão da realidade.

Desse modo, fica clara a importância dos(as) professores(as) juntamente com os(as) alunos(as) atuarem de forma criativa e propositiva não somente no espaço da academia, bem como nos processos das lutas sociais, com vistas à ampliação de direitos e formas de resistência. Nesse contexto, é necessário pensar a educação de forma crítica para que mudanças sociais possam ser vistas.

Nas palavras de hooks (2013, p. 273):

[..] A sala de aula, com todas as suas limitações, continua sendo um ambiente de possibilidades. Nesse campo de possibilidades, temos a oportunidade de trabalhar pela liberdade, de exigir de nós e dos nossos camaradas uma abertura da mente e do coração e que nos permita encarar a realidade ao mesmo tempo em que, coletivamente, imaginamos esquemas para cruzar fronteiras, para transgredir. Isso é a educação como prática de liberdade.

Portanto, a leitura de Ensinando a transgredir nos oferece uma reflexão relevante sobre as persistentes desigualdades raciais, a invisibilidade das mulheres negras no campo epistêmico e a importância de que as práticas pedagógicas feministas sempre reconheceram a legitimidade de uma pedagogia que ousa subverter a cisão entre mente e corpo e nos permite estar presentes por inteiro e, consequentemente, com todo o coração, na sala de aula salienta (idem, p. 256). Assim, é um livro necessário para pensar os impactos das construções teóricas europeias/hegemônicas em sala de aula e a importância de que o ensino seja conduzido com vistas a romper com as heranças coloniais.

\section{REFERENCIAS}

CRENSHAW, Kimberle. Documento para o encontro de especialistas em aspectos da discriminação racial relativos ao gênero. In: Estudos Feministas. No 10. São Paulo, 2002.

hooks, bell. Ensinando a transgredir: a educação como prática da liberdade. São Paulo Martins Fontes, 2013. 
${ }^{i}$ Bacharela em Serviço Social pela Universidade do Estado do Rio Grande do Norte -(UERN). Pós-graduada em Saúde Pública com Ênfase em Saúde da Família pela instituição Faculdade Vale do Jaguaribe.macianafreitas@hotmail.com ORCID https://orcid.org/0000-0003-2291-0411

ii Licenciada em Ciências Sociais pela UERN. Mestranda no Programa de Pós-Graduação em Ensino (PPGE), do Campus Avançado "Profa. Maria Elisa de A. Maia" (CAMEAM). patyloreraposo@hotmail.com ORCID: https://orcid.org/0000-0002-3923-757X

${ }^{3}$ Para Crenshaw (2002, p. 177), a interseccionalidade: [...] busca capturar as consequências estruturais e dinâmicas da interação entre dois ou mais eixos da subordinação. Ela trata especificamente da forma pela qual o racismo, o patriarcalismo, a opressão de classe e outros sistemas discriminatórios criam desigualdades básicas que estruturam as posições relativas de mulheres, raças, etnias, classes e outras. Além disso, a interseccionalidade trata da forma como as políticas específicas geram opressões que fluem ao longo de tais eixos, constituindo aspectos dinâmicos ou ativos do desempoderamento. 